\title{
Synthesis, spectroscopic and thermal studies of 2,3-naphthalenedicarboxylates of rare earth elements
}

\author{
Z. Rzączyńska $\cdot$ A. Kula $\cdot$ J. Sienkiewicz-Gromiuk • \\ A. Szybiak
}

Received: 30 June 2009/Accepted: 11 June 2010/Published online: 6 July 2010

(C) The Author(s) 2010. This article is published with open access at Springerlink.com

\begin{abstract}
The complexes of rare earth elements with 2,3naphthalenedicarboxylic acid of the formula: $\operatorname{Ln}_{2}\left(\mathrm{C}_{12} \mathrm{H}_{6}\right.$ $\left.\mathrm{O}_{4}\right)_{3} \cdot n \mathrm{H}_{2} \mathrm{O}$, where $\mathrm{Ln}=\mathrm{La}(\mathrm{III})-\mathrm{Lu}(\mathrm{III})$ and $\mathrm{Y}(\mathrm{III}) ; n=3$ for $\mathrm{La}(\mathrm{III}), \mathrm{Ce}(\mathrm{III}) ; n=6$ for $\mathrm{Pr}(\mathrm{III})-\mathrm{Yb}(\mathrm{III})$ and $\mathrm{Y}$ (III) and $n=5$ for $\mathrm{Lu}$ (III) have been synthesized and characterized by elemental analysis, IR spectroscopy, thermal analysis (TG, DTG, DTA and TG-FTIR) and X-ray analysis. They are sparingly soluble in water and stable at room temperature. During heating in air atmosphere, they lose all water molecules in several steps, generally in two or three steps, except for the $\mathrm{La}(\mathrm{III})$ and $\mathrm{Ce}(\mathrm{III})$ complexes which lose all water molecules in one step. The anhydrous compounds are stable up to about $773 \mathrm{~K}$ and then decompose to corresponding oxides. The thermal decomposition is connected with the release of water molecules $(443 \mathrm{~K})$, carbon dioxide $(713 \mathrm{~K})$ and hydrocarbons.
\end{abstract}

Keywords 2,3-Naphthalenedicarboxylate complexes . Lanthanides · IR spectra $\cdot$ Thermal analysis .

TG-FTIR analysis

\section{Introduction}

The construction of inorganic coordination polymeric complexes has developed rapidly in recent years, owing to their interesting molecular topologies and crystal packing motifs [1-5] along with potential applications as functional materials [6-9]. As compared to the d-block transition

Z. Rzączyńska ( $₫)$ · A. Kula · J. Sienkiewicz-Gromiuk · A. Szybiak

Faculty of Chemistry, Maria Curie-Skłodowska University, M.C. Skłodowska Sq.2, 20-031 Lublin, Poland

e-mail: z.rzaczynska@poczta.umcs.lublin.pl metal polymers, lanthanide polymeric complexes are less common, because the high coordination numbers of lanthanide ions may cause difficulty in controlling the synthetic reactions and thereby the structures of the products [10].

However, the fascinating coordination geometry and the interesting structures along with the special properties of lanthanide polymeric complexes have attracted increasing interest of chemists, and many studies have been reported in literature.

This article deals with lanthanide complexes with 2,3naphthalenedicarboxylic acid, which is an asymmetrical dicarboxylic acid compound used in the assembly of coordination polymers.

In constructing coordination polymers, aromatic dicarboxylic acids such as 1,4-naphthalenedicarboxylic acid [11, 12], 2,6-naphthalenedicarboxylic acid [13-16] and one of the asymmetrical benzenedicarboxylic acids, 1,2-benzenedicarboxylic acid [17-20], are used extensively in the synthesis of coordination polymers with lanthanide ions. In particular, dicarboxylate of benzene or naphthalene, with different coordination preferences, offers many advantages in the construction of highly porous and robust metalorganic frameworks [21, 22].

As known, lanthanide ions having high affinity for hard donor atoms, and ligands containing oxygen atoms, especially multicarboxylate ligands, are usually employed in the architectures for lanthanide polymeric complexes. 2,3Naphthalenedicarboxylic acid possesses several interesting characteristics: (a) It has two carboxyl groups that may be completely or partially deprotonated, inducing rich coordination modes and allowing interesting structures with higher dimensions. (b) It can act not only as a hydrogen bond acceptor, but also as a hydrogen bond donor, depending upon the number of deprotonated carboxyl 
groups. (c) One of the carboxylate groups is coplanar with the naphthalene rings and the other group is perpendicular to the naphthalene rings. (d) The single unique carboxylic acid group is involved in a cyclic-dimer hydrogen bond across a center of inversion. The long dimension of the 2,3naphthalenedicarboxylic acid molecules is parallel to the $b$ direction, since the twofold axes of the space group (C2/c) are coincident with each molecule. The molecules are arranged in stacks with the naphthalene cores nearly parallel to the (102) plane, and separated by a distance equal to one half of the $c$-axis length. The acid groups, rotated out of the plane of the naphthalene rings, connect adjacent stacks through cyclic-dimer hydrogen bonding across the inversion centers, thus producing a zigzag pattern along the [101] direction [23].

The aim of our work was to prepare the complexes of lanthanides (III) from $\mathrm{La}$ to $\mathrm{Lu}$ and $\mathrm{Y}$ with 2,3-naphthalenedicarboxylic acid as solids and to study their thermal decomposition in air as well as the influence of the metal on the properties of the complexes in the lanthanide series.

\section{Experimental}

Preparation of $\mathrm{Ln}_{2}\left(\mathrm{C}_{12} \mathrm{H}_{6} \mathrm{O}_{4}\right)_{3} \cdot n \mathrm{H}_{2} \mathrm{O}$

Due to insolubility of 2,3-naphthalenedicarboxylic acid in water, we prepared its ammonium salt $(\mathrm{pH}=5.8)$ to obtain the soluble form of the ligand. Ammonium salt of the acid was added to an aqueous solution of lanthanide chloride while stirring. For the preparation of the complexes, the following oxides of rare earth elements were used: $\mathrm{La}_{2} \mathrm{O}_{3}$, $\mathrm{Pr}_{6} \mathrm{O}_{11}, \mathrm{Nd}_{2} \mathrm{O}_{3}, \mathrm{Sm}_{2} \mathrm{O}_{3}, \mathrm{Eu}_{2} \mathrm{O}_{3}, \mathrm{Gd}_{2} \mathrm{O}_{3}, \mathrm{~Tb}_{4} \mathrm{O}_{7}, \mathrm{Dy}_{2} \mathrm{O}_{3}$, $\mathrm{Ho}_{2} \mathrm{O}_{3}, \mathrm{Er}_{2} \mathrm{O}_{3}, \mathrm{Tm}_{2} \mathrm{O}_{3}, \mathrm{Yb}_{2} \mathrm{O}_{3}, \mathrm{Lu}_{2} \mathrm{O}_{3}$ and $\mathrm{Y}_{2} \mathrm{O}_{3}$ (Aldrich Chemical Company); only cerium was used as $\mathrm{Ce}\left(\mathrm{NO}_{3}\right)_{3}$. The 2,3-naphthalenedicarboxylic acid used for preparation was produced by Aldrich Chemical Company. The resulting precipitate of the compound was stirred for an hour at room temperature for recrystallization of powder crystal compound. Then the complex was filtred off, washed with hot water to remove ammonium ions (Nessler control) and dried at $303 \mathrm{~K}$ to constant mass for 2 days. The compounds were identified by the method of elemental analysis (with a Perkin-Elmer CHN 2400 elemental analyzer) and on the base of IR spectra recorded over the range of 4000$400 \mathrm{~cm}^{-1}$ in $\mathrm{KBr}$ discs by using a FTIR $1725 \times$ PerkinElmer spectrophotometer. The X-ray diffraction patterns were taken on a Seifert-DRON automated X-ray diffractometer at ambient temperature.

The thermal stability and decomposition of the lanthanide naphthalenedicarboxylates was investigated with the aid of a Setsys 16/18 (Setaram) thermal analyzer, recording the TG/DTA/DTG or TG/DSC/DTG curves. The samples
(8-9 mg) were heated in a ceramic crucible between 303-973 $\mathrm{K}$ in flowing air atmosphere with a heating rate of $5 \mathrm{~K} \mathrm{~min}^{-1}$. The products of decomposition were postulated on the basis of the TG curves. The purpose of TG/ DSC/DTG analysis was to determine the enthalpy of dehydration process.

\section{Results and discussion}

2,3-Naphthalenedicarboxylates of Y(III) and lanthanides (III) from La to Lu were obtained as crystalline compounds (without complexes of $\mathrm{La}$ and $\mathrm{Ce}$, which are amorphous compounds) with the metal:ligand ratio of $2: 3$ and the general formula of $\mathrm{Ln}_{2}\left[\mathrm{C}_{12} \mathrm{H}_{6} \mathrm{O}_{4}\right]_{3} \cdot n \mathrm{H}_{2} \mathrm{O}$ where $n=3$ for La and $\mathrm{Ce}, n=6$ for $\mathrm{Pr}-\mathrm{Yb}$ (and $\mathrm{Y}$ ), where one can distinguish two isostructural series, the first from Pr to Er (and $\mathrm{Y}$ ), and the second one for the complexes of Tm and $\mathrm{Yb}$. The complex of Lu differs from the remaining complexes and it possesses $n=5$ particles of water.

\section{Infrared spectroscopy}

The complexes were characterized by IR spectroscopy (Table 1). All the 2,3-naphthalenedicarboxylates of rare earth elements (and Y) show similar solid state IR spectra. However, the characteristic frequencies related to the carbonyl group are altered markedly in passing from the acid to the salt.

Table 1 Frequencies for characteristic absorption bands in the IR spectra of lanthanides (III), Y(III) and $\mathrm{Na}(\mathrm{I})$ complexes with 2,3naphthalenedicarboxylic acid $\left(\mathrm{L}=\mathrm{C}_{12} \mathrm{H}_{6} \mathrm{O}_{4}{ }^{2-}\right)$

\begin{tabular}{|c|c|c|c|c|c|c|c|}
\hline Complex & $v_{\mathrm{OH}}$ & $v_{\mathrm{COOH}}$ & $\delta_{\mathrm{H} 2 \mathrm{O}}$ & $v_{\mathrm{as}(\mathrm{COO})}^{-}$ & $v_{\mathrm{s}(\mathrm{COO})}^{-}$ & $v_{\mathrm{M}-\mathrm{O}}$ & $\Delta v_{(\mathrm{COO})}^{-}$ \\
\hline $\mathrm{H}_{2} \mathrm{~L}$ & $\begin{array}{r}3200- \\
2500\end{array}$ & 1700 & 1632 & & 1400 & & \\
\hline $\mathrm{Na}_{2} \mathrm{~L}$ & 3408 & & 1620 & 1563 & 1412 & & 151 \\
\hline $\mathrm{La}_{2} \mathrm{~L}_{3} \cdot 3 \mathrm{H}_{2} \mathrm{O}$ & 3424 & & 1620 & 1538 & 1412 & 480 & 126 \\
\hline $\mathrm{Ce}_{2} \mathrm{~L}_{3} \cdot 3 \mathrm{H}_{2} \mathrm{O}$ & 3408 & & 1620 & 1536 & 1416 & 480 & 120 \\
\hline $\mathrm{Pr}_{2} \mathrm{~L}_{3} \cdot 6 \mathrm{H}_{2} \mathrm{O}$ & 3424 & & 1620 & 1536 & 1412 & 472 & 124 \\
\hline $\mathrm{Nd}_{2} \mathrm{~L}_{3} \cdot 6 \mathrm{H}_{2} 0$ & 3408 & & 1620 & 1536 & 1412 & 472 & 124 \\
\hline $\mathrm{Sm}_{2} \mathrm{~L}_{3} \cdot 6 \mathrm{H}_{2} \mathrm{O}$ & 3376 & & 1620 & 1540 & 1411 & 472 & 129 \\
\hline $\mathrm{Eu}_{2} \mathrm{~L}_{3} \cdot 6 \mathrm{H}_{2} 0$ & 3408 & & 1620 & 1548 & 1418 & 472 & 130 \\
\hline $\mathrm{Gd}_{2} \mathrm{~L}_{3} \cdot 6 \mathrm{H}_{2} \mathrm{O}$ & 3384 & & 1620 & 1548 & 1412 & 472 & 136 \\
\hline $\mathrm{Tb}_{2} \mathrm{~L}_{3} \cdot 6 \mathrm{H}_{2} \mathrm{O}$ & 3408 & & 1620 & 1544 & 1408 & 472 & 136 \\
\hline $\mathrm{Dy}_{2} \mathrm{~L}_{3} \cdot 6 \mathrm{H}_{2} \mathrm{O}$ & 3416 & & 1620 & 1532 & 1406 & 472 & 126 \\
\hline $\mathrm{Ho}_{2} \mathrm{~L}_{3} \cdot 6 \mathrm{H}_{2} \mathrm{O}$ & 3416 & & 1620 & 1536 & 1405 & 472 & 129 \\
\hline $\mathrm{Er}_{2} \mathrm{~L}_{3} \cdot 6 \mathrm{H}_{2} 0$ & 3392 & & 1620 & 1548 & 1411 & 472 & 135 \\
\hline $\mathrm{Tm}_{2} \mathrm{~L}_{3} \cdot 6 \mathrm{H}_{2} \mathrm{O}$ & 3400 & & 1620 & 1532 & 1405 & 472 & 127 \\
\hline $\mathrm{Yb}_{2} \mathrm{~L}_{3} \cdot 6 \mathrm{H}_{2} \mathrm{O}$ & 3408 & & 1620 & 1536 & 1412 & 472 & 124 \\
\hline $\mathrm{Lu}_{2} \mathrm{~L}_{3} \cdot 5 \mathrm{H}_{2} \mathrm{O}$ & 3384 & & 1620 & 1542 & 1408 & 472 & 134 \\
\hline $\mathrm{Y}_{2} \mathrm{~L}_{3} \cdot 6 \mathrm{H}_{2} \mathrm{O}$ & 3408 & & 1620 & 1542 & 1420 & 472 & 122 \\
\hline
\end{tabular}


In the sodium and lanthanide compounds, the following bands, present in the spectra of the free acid, have disappeared: (a) $v(\mathrm{C}=\mathrm{O})$ at $1696 \mathrm{~cm}^{-1}$, (b) $v(\mathrm{OH})$ at 3071,3009 , 2896, 2662 and $2547 \mathrm{~cm}^{-1}, \delta(\mathrm{OH})$ at $1452 \mathrm{~cm}^{-1}$ and $\gamma(\mathrm{OH})$ at $905 \mathrm{~cm}^{-1}$, and (c) $v(\mathrm{C}-\mathrm{O})$ at $1288 \mathrm{~cm}^{-1}$. The bands present in the metal compounds but not the free acid were at $1552-1520$ and $1420-1400 \mathrm{~cm}^{-1}$, assigned, respectively, to asymmetric $\left(v_{\mathrm{as}}\right)$ and symmetric $\left(v_{\mathrm{s}}\right)$ stretching vibrations of the carboxylate group [24, 25]. This clearly indicates that hydrogen was displaced by metal from the carboxylic group. The magnitudes of the separation, $\Delta v$, between the frequencies $v_{\mathrm{as}}(\mathrm{OCO})$ and $v_{\mathrm{s}}(\mathrm{OCO})$ in the complexes are lower $\left(\Delta v(\mathrm{OCO})=144-104 \mathrm{~cm}^{-1}\right)$ than in the sodium salt $\left(\Delta v(\mathrm{OCO})=151 \mathrm{~cm}^{-1}\right)$ which indicates a lower degree of ionic bonding in the rare earth element 2,3naphthalenedicarboxylates. According to spectroscopic criteria [26-28] and with regard to Nakamoto criterion, the carboxylate ion appears to be a bidentate chelating ligand.

In the spectrum of 2,3-naphthalenedicarboxylic acid, there are six bands of the aromatic system in the 1640 $1370 \mathrm{~cm}^{-1}$ region at the frequencies of $1626,1589,1573$, $1510,1472,1398 \mathrm{~cm}^{-1}$. In sodium 2,3-naphthelenedicarboxylate, three bands appears at 1607,1495 and $1361 \mathrm{~cm}^{-1}$. In the complexes of light lanthanides the aromatic system bands appear at 1470 and $1348 \mathrm{~cm}^{-1}$. In the complexes of heavy lanthanides, there are also two maxima which appear at 1480 and $1353 \mathrm{~cm}^{-1}$.

In the range of $1190-1050 \mathrm{~cm}^{-1}$ the bands from skeletal vibrations of the aromatic system $\beta(\mathrm{CH})$ can be observed. Moving towards lower frequencies one can distinguish the next range $\left(970-700 \mathrm{~cm}^{-1}\right)$, there the bands from $\gamma(\mathrm{CH})$ groups are observed. The symbol $\beta$ denotes deformation in plane vibrations of functional groups and $\gamma$ denotes out-ofplane vibrations [29]. Vibrations of the aromatic ring denoting deformation out-of-plane $\phi(\mathrm{CC})$ appear at frequencies $700-650 \mathrm{~cm}^{-1}$, and they are more numerous in free acid spectra.

These results indicate that the character of the bonds between the metal and the carboxylic groups affects the distribution of the electron charge in the aromatic ring [30]. The absence of bands of the aromatic system and the decrease in intensity or their shift towards lower wavenumbers (caused by weakening of the bonds) is the evidence of perturbation of the aromatic system [31-34].

Bands due to the metal-oxygen bond appears at 480 $472 \mathrm{~cm}^{-1}$ for the whole series of complexes. Therefore, it is possible to assume that 2,3-naphthalededicarboxylic acid forms complexes with rare elements of similar stability [35].

X-ray powder diffraction

Analysis of the diffractograms suggests that 2,3-naphthalenediacarboxylates of rare earth elements are polycrystalline

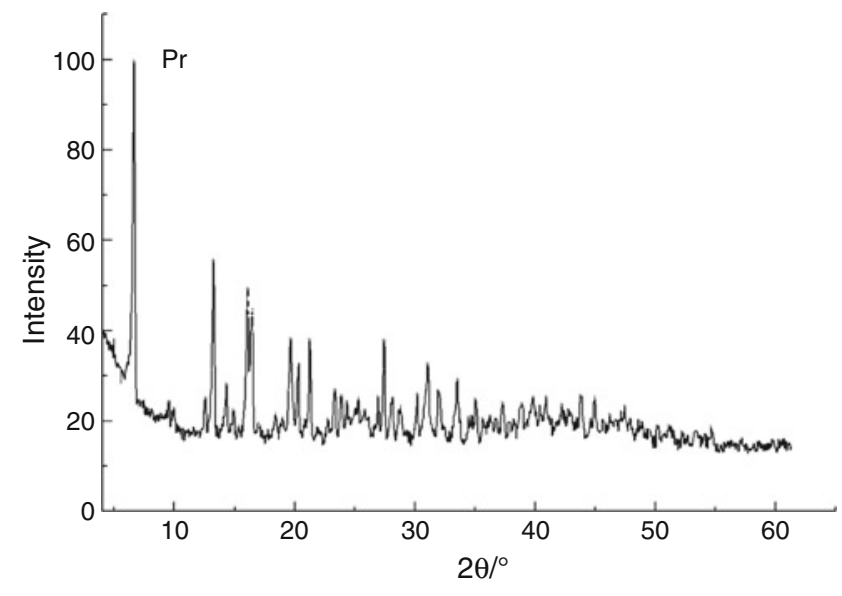

Fig. 1 X-ray powder diffraction patterns of $\operatorname{Pr}_{2}\left(\mathrm{C}_{12} \mathrm{H}_{6} \mathrm{O}_{4}\right)_{3} \cdot 6 \mathrm{H}_{2} \mathrm{O}$

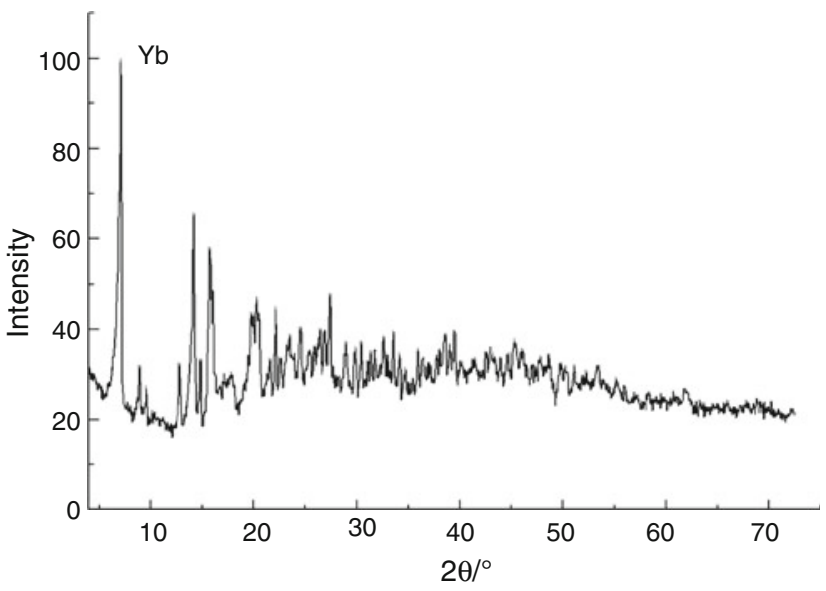

Fig. 2 X-ray powder diffraction patterns of $\mathrm{Yb}_{2}\left(\mathrm{C}_{12} \mathrm{H}_{6} \mathrm{O}_{4}\right)_{3} \cdot 6 \mathrm{H}_{2} \mathrm{O}$

compounds. The structure of the compounds has not been determined as single crystals have not been obtained (Figs. 1, 2).

One can distinguish the three isostructural series of these compounds: hexahydrated complexes from $\mathrm{Pr}$ to $\mathrm{Er}$, hexahydrated complexes of $\mathrm{Tm}$ and $\mathrm{Yb}$ make up the second series, and the third series in which there is only one pentahydrated complex of Lu.

2,3-Naphthalenediacarboxylates of $\mathrm{La}$ and $\mathrm{Ce}$ are amorphous compounds, which can be assigned to separate series.

Thermogravimetric analysis

Thermogravimetric analysis was performed to investigate the thermal stability of the complexes under consideration. The results are presented in Table 2. The results obtained from their thermal decomposition show them to be hydrated salts. They usually possess six molecules of water (except $\mathrm{La}, \mathrm{Ce}-$ three molecules, and $\mathrm{Lu}-$ five). Their 
Table 2 Thermal decomposition of lanthanides (III) and Y(III) complexes with 2,3-naphthalenedicarboxylic acid (air atmosphere)

\begin{tabular}{|c|c|c|c|c|c|c|c|c|}
\hline \multirow[t]{2}{*}{ Complex } & \multirow[t]{2}{*}{$M / \mathrm{mol}$} & \multirow[t]{2}{*}{$\Delta T_{1} / \mathrm{K}$} & \multicolumn{2}{|c|}{ Mass loss $\%$} & \multirow[t]{2}{*}{$T_{\mathrm{b}} / \mathrm{K}$} & \multirow[t]{2}{*}{$T_{\mathrm{o}} / \mathrm{K}$} & \multicolumn{2}{|c|}{ Residue \% } \\
\hline & & & Calc. & Found & & & Calc. & Found \\
\hline $\mathrm{La}_{2} \mathrm{~L}_{3} \cdot 3 \mathrm{H}_{2} \mathrm{O}$ & 974.3 & $323-423$ & 5.54 & 5.31 & 613 & 823 & 33.25 & 31.27 \\
\hline $\mathrm{Ce}_{2} \mathrm{~L}_{3} \cdot 3 \mathrm{H}_{2} \mathrm{O}$ & 976.7 & $323-423$ & 5.53 & 4.46 & 623 & 713 & 37.30 & 36.52 \\
\hline $\mathrm{Pr}_{2} \mathrm{~L}_{3} \cdot 6 \mathrm{H}_{2} \mathrm{O}$ & 1032.8 & $333-433$ & 10.47 & 10.88 & 673 & 823 & 33.00 & 31.27 \\
\hline $\mathrm{Nd}_{2} \mathrm{~L}_{3} \cdot 6 \mathrm{H}_{2} \mathrm{O}$ & 1039.0 & $323-453$ & 10.40 & 11.63 & 673 & 823 & 32.42 & 32.65 \\
\hline $\mathrm{Sm}_{2} \mathrm{~L}_{3} \cdot 6 \mathrm{H}_{2} \mathrm{O}$ & 1051.4 & $323-463$ & 10.28 & 10.73 & 663 & 773 & 33.19 & 31.74 \\
\hline $\mathrm{Eu}_{2} \mathrm{~L}_{3} \cdot 6 \mathrm{H}_{2} 0$ & 1054.4 & $323-433$ & 10.25 & 10.57 & 633 & 743 & 33.40 & 34.87 \\
\hline $\mathrm{Gd}_{2} \mathrm{~L}_{3} \cdot 6 \mathrm{H}_{2} \mathrm{O}$ & 1065.0 & $323-473$ & 10.15 & 11.11 & 673 & 763 & 34.05 & 33.99 \\
\hline $\mathrm{Tb}_{2} \mathrm{~L}_{3} \cdot 6 \mathrm{H}_{2} 0$ & 1068.3 & $323-463$ & 10.11 & 10.53 & 663 & 763 & 35.02 & 36.29 \\
\hline $\mathrm{Dy}_{2} \mathrm{~L}_{3} \cdot 6 \mathrm{H}_{2} \mathrm{O}$ & 1075.6 & $323-443$ & 10.04 & 9.93 & 663 & 763 & 35.06 & 37.34 \\
\hline $\mathrm{Ho}_{2} \mathrm{~L}_{3} \cdot 6 \mathrm{H}_{2} \mathrm{O}$ & 1080.5 & $323-473$ & 10.00 & 10.70 & 663 & 773 & 34.99 & 35.85 \\
\hline $\mathrm{Er}_{2} \mathrm{~L}_{3} \cdot 6 \mathrm{H}_{2} 0$ & 1085.1 & $323-473$ & 9.96 & 10.28 & 663 & 773 & 35.27 & 37.04 \\
\hline $\mathrm{Tm}_{2} \mathrm{~L}_{3} \cdot 6 \mathrm{H}_{2} \mathrm{O}$ & 1088.4 & $323-463$ & 9.93 & 10.13 & 663 & 783 & 35.47 & 36.98 \\
\hline $\mathrm{Yb}_{2} \mathrm{~L}_{3} \cdot 6 \mathrm{H}_{2} \mathrm{O}$ & 1096.6 & $323-473$ & 9.85 & 10.02 & 663 & 783 & 35.95 & 36.48 \\
\hline $\mathrm{Lu}_{2} \mathrm{~L}_{3} \cdot 5 \mathrm{H}_{2} 0$ & 1082.5 & $323-453$ & 8.33 & 8.23 & 633 & 823 & 36.85 & 37.75 \\
\hline $\mathrm{Y}_{2} \mathrm{~L}_{3} \cdot 6 \mathrm{H}_{2} \mathrm{O}$ & 928.4 & $323-433$ & 11.64 & 11.66 & 633 & 783 & 24.35 & 25.14 \\
\hline
\end{tabular}

$\Delta T_{1}$ temperature range of dehydration process, $T_{b}$ temperature of beginning of decomposition, $T_{o}$ temperature of oxide formation

chemical composition has been confirmed by elementary analysis. On heating in air atmosphere they lose all water molecules in several steps, generally in two steps (Fig. 3), except for the complexes: La(III), Ce(III), Eu(III), Dy(III), $\mathrm{Lu}(\mathrm{III})$ and $\mathrm{Y}(\mathrm{III})$ which lose all water molecules in one step and those of $\mathrm{Tm}$ (III) and $\mathrm{Yb}(\mathrm{III})$ which lose them in three steps. The coordination sphere can include two or three water molecules and the others are in the hydrogen bonded outer coordination sphere of the complex.

Taking into consideration, a general rule in lanthanide complex binding, by the coordination number 8 or 9 of lanthanide (III) ions, only five or six coordination sites are saturated with oxygen atoms of acid anions, but two or three sites can be saturated with water oxygens. So, the

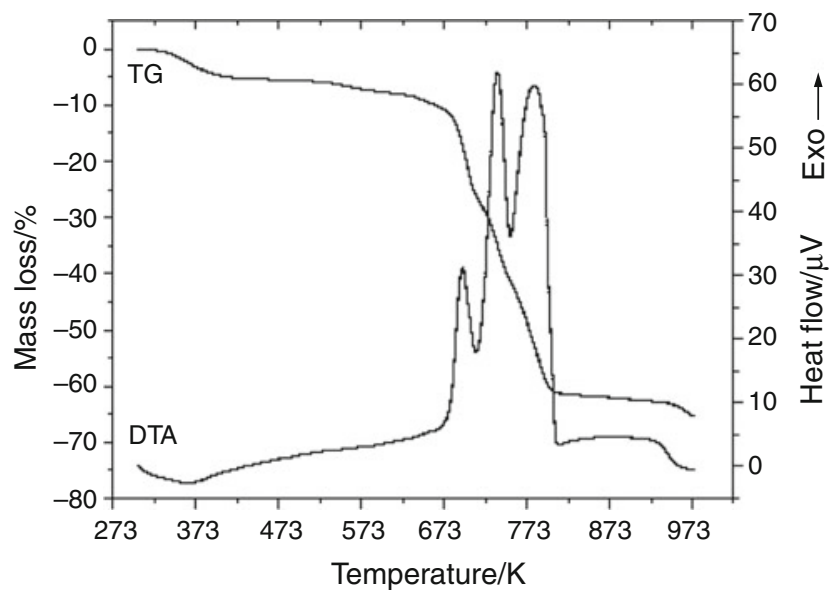

Fig. 3 TG and DTA curves of thermal decomposition of $\mathrm{La}_{2}$ $\left(\mathrm{C}_{12} \mathrm{H}_{6} \mathrm{O}_{4}\right)_{3} \cdot 3 \mathrm{H}_{2} \mathrm{O}$ inner coordination sphere can include two or three water molecules and the others are in the hydrogen bonded outer coordination sphere of the complex.

The energy of coordination water molecules bonding is higher than that of hydrogen bonded water molecules in the second coordination sphere. This way of coordination in some cases affects the way of dehydratation process-the complexes lose the hydrogen-bonded water molecules in the first step and the covalent-bonded water molecules from the first coordination sphere in the next one [36]. A shape of DTG and DTA curves indicate the presence of this stage of dehydratation (Fig. 4). This process is connected with an endothermic effect shown by the DTA curves. The found mass losses estimated for the dehydratation process

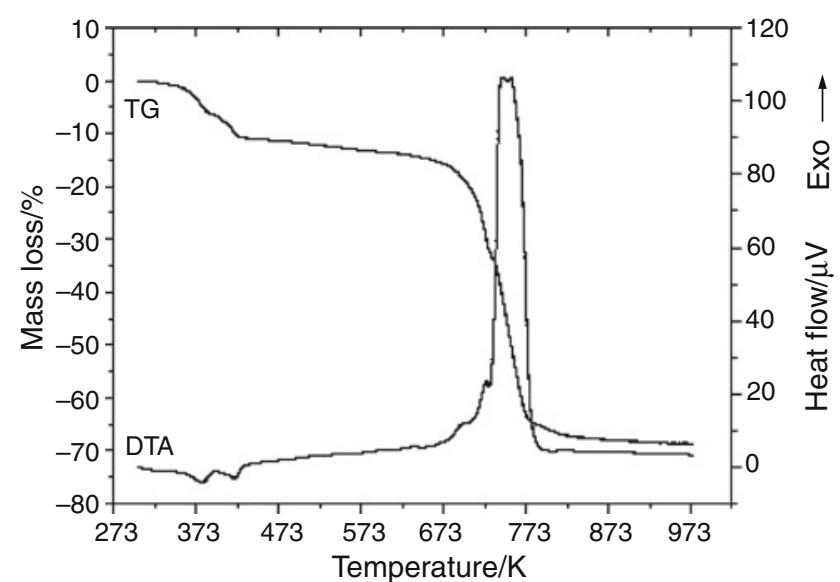

Fig. 4 TG and DTA curves of thermal decomposition of $\operatorname{Pr}_{2}\left(\mathrm{C}_{12}\right.$ $\left.\mathrm{H}_{6} \mathrm{O}_{4}\right)_{3} \cdot 6 \mathrm{H}_{2} \mathrm{O}$ 


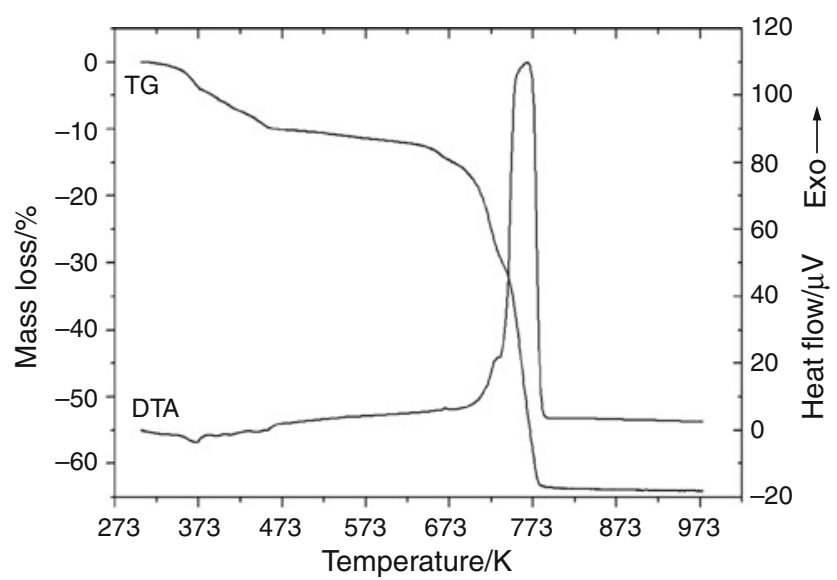

Fig. 5 TG and DTA curves of thermal decomposition of $\mathrm{Yb}_{2}$ $\left(\mathrm{C}_{12} \mathrm{H}_{6} \mathrm{O}_{4}\right)_{3} \cdot 6 \mathrm{H}_{2} \mathrm{O}$

from the TG curves (without $\mathrm{La}$ and $\mathrm{Ce}$ complexes) are equal to $8.23-11.67 \%$ (theoretical: 8.33-11.64\%). The anhydrous complexes are stable up to $613-673 \mathrm{~K}$ and then they decompose. The 2,3-naphthalenedicaroxylates of Sm, $\mathrm{Gd}, \mathrm{Tb}, \mathrm{Dy}, \mathrm{Ho}, \mathrm{Er}, \mathrm{Tm}, \mathrm{Yb}, \mathrm{Lu}$ and $\mathrm{Y}$ decompose to suitable oxides $\mathrm{Ln}_{2} \mathrm{O}_{3}(\mathrm{Ln}=\mathrm{Sm}, \mathrm{Gd}$, Dy, $\mathrm{Ho}, \mathrm{Er}, \mathrm{Tm}, \mathrm{Yb}$, $\mathrm{Lu}$ and $\mathrm{Y}$ ) and $\mathrm{Tb}_{4} \mathrm{O}_{7}$ via the intermediate formation of the oxycarbonates of lanthanides $\mathrm{Ln}_{2} \mathrm{O}_{2} \mathrm{CO}_{3}$ (except for $\mathrm{Tb}_{4} \mathrm{O}_{6} \mathrm{CO}_{3}$ ). The peaks ascribed to the mass losses seen on the TG curves at 693-723 $\mathrm{K}$ are also recorded in the DTG curves, which is the first derivative of the formation of various intermediate products of decomposition (Fig. 5).

The combustion of organic ligands is accompanied by strong exo-effects seen on the DTA curves. The large peaks recorded in the curves of DTG correspond to the gradual mass loss of the complexes during heating.

The remaining complexes, which are 2,3-naphthalenedicaroxylates of $\mathrm{La}, \mathrm{Ce}, \mathrm{Pr}, \mathrm{Nd}$ and $\mathrm{Eu}$ decompose to suitable oxides without indirect stages.

The temperature of oxides formation is in the range $713-823 \mathrm{~K}$. The mass loss determined from the TG curve is equal to $63.00 \%$. The oxidation process is associated with a strong exothermic effect reflected on the DTA curve.

\section{TG-FTIR analysis}

The decomposition process connected with the gas product analysis was carried out for the $\mathrm{Sm}$ and Ho complexes. The FTIR spectrum of gaseous products is presented in Fig. 6 .

These spectra confirm that at first dehydratation takes place. As follows from Fig. 6 in the spectrum of gaseous products of decomposition, in the ranges of 3750-3500 and $1800-1300 \mathrm{~cm}^{-1}$, stretching and deformation vibrations appear due to $\mathrm{H}_{2} \mathrm{O}$ molecules absorption. These bands disappear above $170{ }^{\circ} \mathrm{C}$ when the anhydrous compound is

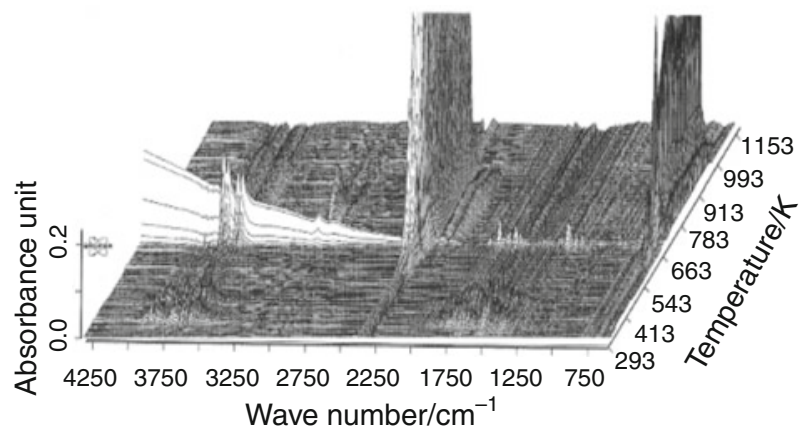

Fig. 6 FTIR spectra of gaseous products of thermal decomposition of $\mathrm{Ho}_{2}\left(\mathrm{C}_{12} \mathrm{H}_{6} \mathrm{O}_{4}\right)_{3} \cdot 6 \mathrm{H}_{2} \mathrm{O}$

formed. The anhydrous compound is stable up to $693 \mathrm{~K}$. When the complex is heated above $713 \mathrm{~K}$, the subsequent decomposition of the compound with degradation of organic ligand takes place. The first step of organic ligand decomposition is release of $\mathrm{CO}_{2}$ which is reflected in the FTIR spectra recorded at $713 \mathrm{~K}$. Carbon dioxide molecules absorb in the wave number in the ranges $2300-2250 \mathrm{~cm}^{-1}$ and $750-600 \mathrm{~cm}^{-1}$ due to deformation and valence vibrations [37]. With the increasing temperature, the molecules of $\mathrm{CO}$ are released and their characteristic absorption bands occur in the range $2220-2060 \mathrm{~cm}^{-1}[38,39]$. The analysis of FTIR spectra of hydrated complexes shows that with the rise of temperature the water molecules are lost which is confirmed by the bands in the range $3900-3400 \mathrm{~cm}^{-1}$ [40].

\section{Conclusions}

In conclusion, the novel coordination lanthanide (III) complexes with 2,3-naphthalenedicarboxylic acid have been synthesized and characterized. The solid complexes crystallize in the three isostructural series: hexahydrated compounds from $\operatorname{Pr}(\mathrm{III})$ to $\operatorname{Er}(\mathrm{III})$; hexahydrated compounds of $\mathrm{Tm}$ (III) and $\mathrm{Yb}(\mathrm{III})$ make up the second series, and the third series with only one complex made up by the pentahydrated complex of $\mathrm{Lu}(\mathrm{III})$.

2,3-Naphthalenediacrboxylates of $\mathrm{La}(\mathrm{III})$ and $\mathrm{Ce}(\mathrm{III})$ are amorphous compounds, which can be assigned to a separate series.

The coordination metal ion-ligand occurs through oxygen atoms of carboxylic groups. Heated in air, the complex loses all water molecules generally in one or two steps (except for $\mathrm{Tm}$ and $\mathrm{Yb}$ - in three steps). The studies conducted showed that the compounds obtained are stable but they easily dehydrate. The anhydrous compounds are stable in a wide range of temperature from $423 \mathrm{~K}$ to about $673 \mathrm{~K}$, heated decompose to oxides. For further thermal studies, the compounds which lose all water molecules at one stage were selected. They are sparingly soluble in water. The 
most slightly soluble in water is the complex of Eu, which has the smallest value of water solubility, while the complex of La has be highest.

Open Access This article is distributed under the terms of the Creative Commons Attribution Noncommercial License which permits any noncommercial use, distribution, and reproduction in any medium, provided the original author(s) and source are credited.

\section{References}

1. Hagrman PJ, Hagrman D, Zubieta J. Organic-inorganic hybrid materials: from "simple" coordination polymers to organodiamine-templated molybdenum oxides. J. Angew Chem. 1999;38: 2639-84.

2. Batten SR, Robson R. Interpenetrating nets: ordered, periodic entanglement. Angew Chem. 1998;37:1460-94.

3. Yaghi OM, Li H, Davis C, Richardson D, Groy TL. Synthetic strategies, structure patterns, and emerging properties in the chemistry of modular porous solids. Acc Chem Res. 1998;31:474-84.

4. Munakata M, Wu L, Kuroda-Sowa T. Toward the construction of functional solid-state supramolecular metal complexes containing copper(I) and silver(I). Adv Inorg Chem. 1999;46:173-303.

5. Blake AJ, Champness NR, Hubberstey P, Li WS, Withersby MA, Schroer M. Inorganic crystal engineering using self-assembly of tailored building-blocks. Coord Chem Rev. 1999;183:117-38.

6. Sato O, Iyoda T, Fujishima A, Hashimoto K. Photoinduced magnetization of a cobalt-iron cyanide. Science. 1996;272:704-5.

7. Kahn O, Martinez C. Spin-transition polymers: from molecular materials toward memory devices desalination. Science. 1998; 279:44-8

8. Evans OR, Xiong R, Wang Z, Wong GK, Lin W. Crystal engineering of acentric diamondoid metal-organic coordination networks. Angew Chem. 1999;38:536-8.

9. Fujita M, Kwon YJ, Washizu S, Ogura K. Preparation, clathration ability, and catalysis of a two-dimensional square network material composed of cadmium(II) and 4,4'-bipyridine. J Am Chem Soc. 1994;116:1151-2.

10. Long DL, Blade AJ, Champness NR, Schoder M. Lanthanide co-ordination frameworks of 4,4'-bipyridine- $N, N^{\prime}$-dioxide. Chem Commun 2000;1369-70.

11. Zheng X-J, Jin L-P, Gao S, Lu S-Z. New ternary lanthanide coordination polymers of 1,4-naphthalenedicarboxylate with 1,10-phenanthroline. Inorg Chem Commun. 2005;8:72-5.

12. Zheng X-J, Jin L-P, Gao S, Lu S-Z. Second ligand-directed selfassembly of lanthanide (III) coordination polymers with 1,4naphthalenedicarboxylate. New J Chem (Nouv J Chim). 2005;29: 798-804.

13. Wang Z, Jin C-M, Shao T, Li Y-Z, Zhang K-L, Zhang H-T, You $\mathrm{X}-\mathrm{Z}$. Syntheses, structures, and luminescence properties of a new family of three-dimensional open-framework lanthanide coordination polymers. Inorg Chem Commun 2002;5:642-8.

14. Deluzet A, Maudez W, Daiguebonne C, Guillou O. Interplane distances modulation in lanthanide-based coordination polymers. Cryst Growth Des. 2003;3:475-9.

15. Paz FAA, Klinowski J. Hydrothermal synthesis of a novel thermally stable three-dimensional ytterbium-organic framework. Chem Commun 2003;1484-1485.

16. Min D, Lee SW. 3-dimensional terbium coordination polymers: $\left[\mathrm{Tb}_{4}(\mathrm{NDC}) 6\left(\mathrm{H}_{2} \mathrm{O}\right) 5\right] \cdot 2 \mathrm{H}_{2} \mathrm{O}$ and $\left[\mathrm{Tb}_{2}(\mathrm{BPDC}) 3\left(\mathrm{H}_{2} \mathrm{O}\right) 3\right] \cdot \mathrm{H}_{2} \mathrm{O}$ (NDC $=2,6$-naphthalenedicarboxylate; $\mathrm{BPDC}=2,2^{\prime}$-bipyridine4,4'-dicarboxylate). Bull Korean Chem Soc. 2002;23:948-52.
17. Thirumurugan A, Natarajan S. Terephthalate bridged frameworks of $\mathrm{Nd}$ and $\mathrm{Sm}$ phthalates. Inorg Chem Commun. 2004;7:395-9.

18. Song Y-S, Yan B, Chen Z-X. A novel unexpected two-dimensional layer-like luminescent dysprosium coordination polymer $\left[\mathrm{Dy}_{2}(\text { phth })_{3} \mathrm{H}_{2} \mathrm{O}\right]_{n}$ by hydrothermal synthesis. Can J Chem. 2004; $82: 1745-51$

19. Meng Z-R, Zhang Q-Z, Wu X-Y, Chen L-J, Lu C-Z. Poly[aquabis ( $\mu 4$-benzene-1,2-dicarboxylato)( $\mu 3$-benzene-1,2-dicarboxylato)digadolinium(III)]. Acta Crystallogr Sect E. 2006; 62:m1033-5.

20. Wan Y, Jin L, Wang K, Zhabg L, Zheng X, Lu S. Hydrothermal synthesis and structural studies of novel 2-D lanthanide coordination polymers with phthalic acid. New J Chem (Nouv J Chim) 2002;26:1590-6.

21. Serre C, Millange F, Thouvneot C, Nogues M, Marsolier G, Louer D, Gerey F. Very large breathing effect in the first nanoporous chromium(III)-based solids: MIL-53 or $\mathrm{CrIII}(\mathrm{OH}) \cdot\left\{\mathrm{O}_{2} \mathrm{C}-\right.$ $\left.\mathrm{C}_{6} \mathrm{H}_{4}-\mathrm{CO}_{2}\right\} \cdot\left\{\mathrm{HO}_{2} \mathrm{C}-\mathrm{C}_{6} \mathrm{H}_{4}-\mathrm{CO}_{2} \mathrm{H}\right\} x \cdot \mathrm{H}_{2} \mathrm{O} y$. J Am Chem. 2002; 124:13159-526.

22. Thirumururgan A, Natarajan S. Inorganic-organic hybrid compounds: synthesis and structures of new metal organic polymers synthesized in the presence of mixed dicarboxylates. Eur J Inorg Chem 2004:762-70.

23. Fitzgerald LJ, Gerkin RE. Structure of 2,3-naphthalenedicarboxylic acid. Acta Crystallogr. 1992;C48:1971-5.

24. Nakamoto K, McCathy PI. Spectroscopy and structure of metal chelate compounds. New York: Willey; 1968.

25. Lewandowski W. Effect of lanthanides on the aromatic system of benzoic acid. J Mol Struc. 1983;101:93-103.

26. Manhas BS, Trikha AK. Relationships between the direction of shifts in the carbon-oxygen stretching frequencies of carboxylato complexes and the type of carboxylate coordination. J Indian Chem Soc. 1982;59:315-9.

27. Mekratra RC, Bohra R. Metal carboxylates. London: Academic Press; 1983.

28. Nakamoto K. Infrared and Raman spectra of inorganic and coordination compounds. New York: Wiley; 1986.

29. Lewandowski W, Barańska H, Mościbroda P. Vibrational and electronic spectroscopic study of lanthanides and effect of sodium on the aromatic system of benzoic acid. J Raman Spectrosc. 1986;17:17-22.

30. Burger K. Coordination chemistry: experimental methods. London: Butterworths; 1973. p. 53.

31. Lewandowski W, Barańska H. The influence of selected metals on the aromatic system of salicylic acid. Appl Spectrosc. 1987; 41:976-80.

32. Lewandowski W. A comparison of the influence of some metals on the aromatic system of benzoic acid. Can J Spectrosc. 1987;32:41-5.

33. Lewandowski W, Janowski A. Effect of ionic potentials of metals on perturbation of the aromatic system of benzoic acid. J Mol Struct. 1988;174:201-6.

34. Lewandowski W. A comparison of the effect of toxic and nontoxic metals on the aromatic system of salicylic acid. Can J Spectrosc. 1987;32:95-104.

35. Lewandowski W, Barańska H, Mościbroda P. Vibrational study of nicotinic acid complexes with different central ions. J. Raman Spectrosc. 1993;24:819-24.

36. Brzyska W, Rzączyńska Z, Kula A, Jaroniec M. Spectral and thermal studies of yttrium and heavy lanthanide 2,6-dihydroxybenzoates. Polish J Chem. 1998;72:2524-30.

37. Rzączyńska Z, Woźniak M, Wołodkiewicz W, Ostasz A, Pikus S. Thermal properties of lanthanide(III) complexes with 5-amino1,3-benzenedicarboxylic acid. J Therm Anal Calorim. 2007;88: $871-6$. 
38. Ferenc W, Walków-Dziewulska A, Kuberski SM. Spectral, thermal, and magnetic properties of 2, 3-dimethoxybenzoates of rare earth elements. Chem Pap. 2003;57:322-31.

39. Łyszczek R. Comparison of thermal properties of lanthanide trimellitates prepared by different methods. J Therm Anal Calorim. 2008;93:833-8.
40. Łyszczek R. Thermal and spectroscopic investigations of new lanthanide complexes with 1,2,4-benzenetricarboxylic acid. J Therm Anal Calorim. 2007;90:533-9. 